\title{
EDITORIAL
}

\section{Focus on extracorporeal life support}

\author{
Peter Schellongowski ${ }^{1,2}$, Alain Combes ${ }^{3,4}$ and Morten Hylander Møller ${ }^{5^{*}}$ (B)
}

C 2018 Springer-Verlag GmbH Germany, part of Springer Nature and ESICM

\section{Introduction}

This focus editorial embraces a series of recent publications on extracorporeal life support (ECLS), including state-of-the-art reviews [1], areas of uncertainties [2], challenges in producing clinical evidence [3-5], as well as ethical considerations [6]. Finally, the recent EOLIA trial on the use of veno-venous extracorporeal membrane oxygenation (VV-ECMO) in patients with severe acute respiratory distress syndrome (ARDS) is discussed [7].

\section{Indications for ECLS}

Growing evidence documents the capability of available ECLS modes to effectively restore gas exchange and circulation in pulmonary and/or cardiac failure. VV-ECMO and extracorporeal $\mathrm{CO}_{2}$-removal $\left(\mathrm{ECCO}_{2} \mathrm{R}\right)$ are usually employed in the settings of respiratory failure $[1,8]$, whereas veno-arterial (VA-)ECMO and other short-term percutaneous mechanical circulatory support (MCS) devices are primarily used in patients with cardiogenic shock $[2,9]$. At the extreme end, extracorporeal cardiopulmonary resuscitation with ECMO (ECPR) may be attempted [10]. Principal indications include bridge to recovery, transplantation, as well as preliminary or definite mechanical assist devices.

\section{Open questions}

Available data suggest improved outcome in patients treated with ECLS $[2,8]$. In addition to improved general intensive care management, growing center experience, larger case volumes [11], technical breakthroughs in ECMO equipment, the establishment of the Extracorporeal Life Support Organization (ELSO, https://www. elso.org) and research networks such as the International

\footnotetext{
*Correspondence: mortenhylander@gmail.com

${ }^{5}$ Department of Intensive Care 4131, Copenhagen University Hospital, Rigshospitalet, Copenhagen, Denmark

Full author information is available at the end of the article
}

ECMO Network (http://www.internationalecmonetwork. org), the organization of ECLS programs on a regional and national level $[12,13]$, the establishment of ECMO retrieval teams, and the development of clinical prediction rules have likely contributed to this improvement. Nevertheless, essential questions about specific indications, impact on clinical outcomes, and concerns about safety remain (Fig. 1). In plain language, even though a good rationale to use ECLS measures for several indications does exist, high-quality evidence supporting routine use of ECLS is lacking as of today.

Consequently, a panel of experts have identified a series of randomized controlled trials (RCTs) to be pressing, including on VV-ECMO for severe respiratory failure, VA-ECMO and other MCS devices versus medical treatment for patients with cardiogenic shock, transfusion and anticoagulation strategies, mobilization and physical therapy in ECMO patients, and pre-hospital versus in-hospital ECPR [2]. Other potential topics for RCTs include the role of $\mathrm{ECCO}_{2} \mathrm{R}$ in patients with ARDS or chronic obstructive pulmonary disease. Other uncertainties include LV unloading in VA-ECMO, physiologic studies evaluating optimal ventilation strategies in ECMO, the role of nutrition therapy in ECMO patients, drug pharmacokinetics and pharmacodynamics, and large high-quality studies on adverse events [2].

\section{Role of randomized controlled trials in extracorporeal life support}

While potential targets for research seem to be agreeable among ECLS experts, the appropriate scientific methods are not. In particular, the question whether RCTs are suitable formats to generate clinically relevant evidence in ECLS is a matter of intense debate. "Advocators" of RCTs argue that the highest level of evidence must be sought in high-risk and resource-intense techniques such as ECLS, as alternative designs, including observational studies, are at significant risk of confounding by indication and residual confounding [5]. On the other side,

\section{Springer}



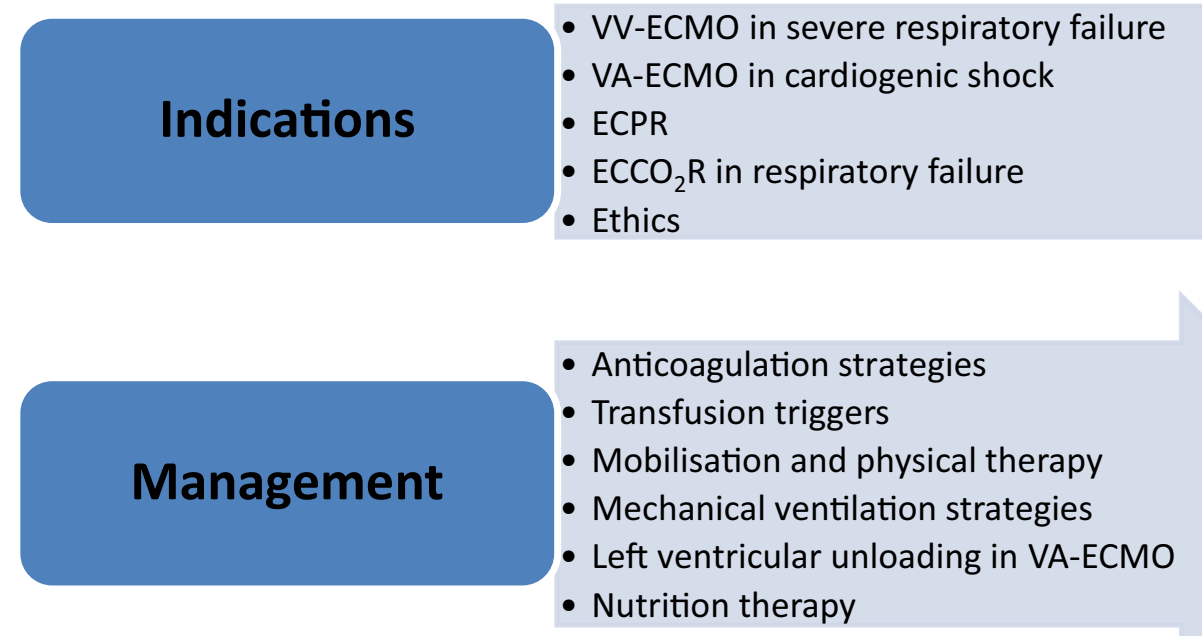

Safety

- Drug pharmacokinetics

- Drug pharmacodynamics

- Adquately powered trials assessing safety

ECCO2R: extracorporeal CO2-removal; ECMO: extracorporeal membrane oxygenation; ECPR: extracorporeal cardiopulmonary resuscitation; VA: venoarterial; VV: veno-venous

Fig. 1 Open questions in extracorporeal life support. ECCO2R extracorporeal $\mathrm{CO}_{2}$-removal, $E C M O$ extracorporeal membrane oxygenation, $E C P R$ extracorporeal cardiopulmonary resuscitation, VA veno-arterial, $W$ veno-venous

"sceptics" argue that, under rescue conditions, including acute life-threatening hypoxia or refractory cardiogenic shock, potentially life-saving interventions should not be prone to randomization due to ethical reasons and lack of equipoise [3]. Furthermore, clinically relevant and realistic treatment effects would necessitate larger sample sizes than in ongoing and existing ECLS trials, which would likely be challenging within a reasonable time frame [3]. Eventually, variabilities concerning ECLS techniques, overall management, centers, and different patient populations may furthermore hamper the interpretation of results derived from RCTs [4], according to "sceptics".

\section{The EOLIA trial}

In the recently published Extracorporeal Membrane Oxygenation in Severe Acute Respiratory Distress Syndrome (EOLIA) trial [7], subjects with very severe ARDS were randomized to ECMO or optimal conventional mechanical ventilation (with control subjects all receiving neuromuscular blockade and 90\% undergoing prone positioning). Although it was terminated early for futility in reaching the primary endpoint of a $20 \%$ absolute reduction in mortality at 60 days, there was a strong indication toward a reduction in mortality (35\% vs. $46 \%$; relative risk 0.76 ; $95 \%$ CI $0.55-1.04$, $p=0.09$ ), as well as a low rate of complications in both groups. Secondary endpoints and post hoc sensitivity and exploratory analyses were all favoring the use of ECMO. Notably, patients with severe hypoxemia (oxygen saturation $<80 \%$ for $>6 \mathrm{~h}$ despite the use of adjunctive therapies, including prone positioning) who crossed over from conventional management to ECMO, had a substantially higher 60-day mortality (57\%) than those in the control group that did not cross over $(41 \%)$ and than those in the ECMO group (35\%) [7].

Open discussions concede that this trial is not "traditionally positive", while "ECMO probably has some benefit" in this context [14]. Other authors argue that "reserving ECMO for patients whose life-threatening hypoxemia persists" despite comprehensive conventional measures seems reasonable, thus acknowledging a place for ECMO at least as a rescue measure in severe ARDS [15]. Likely, meta-analyses incorporating the results of EOLIA will strengthen the evidence on the effectiveness of VV-ECMO in severe ARDS. 


\section{Ethical considerations}

The results of published and ongoing trials and their interpretation enhance our knowledge and view of the potential benefits of different ECLS modes. However, we should not conceal that, under real-life circumstances outside of clinical trials, reasonable indications are stretched and mortality of affected patients seems to be considerably higher [16]. Whenever ECLS does not bear realistic chances of bridging a patient to either recovery or destination therapy like organ transplantation or mechanical assist, futility must be discussed. What if no such option seems attainable and ECLS basically prevents a patient from dying? In these cases, the answer to the question "who decides?" should be sought together with close guidance of patients and relatives, preventive ethics including daily interdisciplinary rounds, advance care planning, and ethics consultation policies in conflicting situations, as well as support by spiritual and palliative care providers [6]. Any center should seek to add respective behaviors, cooperation, structures, and resources on top of their technical ECLS skills.

\begin{abstract}
Author details
${ }^{1}$ Department of Medicine I, Intensive Care Unit 13i2, Medical University of Vienna, Vienna, Austria. ${ }^{2}$ Center of Excellence of Medical Intensive Care (CEMIC), Medical University of Vienna, Vienna, Austria. ${ }^{3}$ Institute of Cardiometabolism and Nutrition, Sorbonne Université INSERM Unité Mixte de Recherche (UMRS) 1166, Paris, France. ${ }^{4}$ Service de Médecine Intensive-Réanimation, Institute de Cardiologie, Assistance Publique-Hôpitaux de Paris (APHP) Hôpital Pitié-Salpêtrière, Paris, France. ${ }^{5}$ Department of Intensive Care 4131, Copenhagen University Hospital, Rigshospitalet, Copenhagen, Denmark.
\end{abstract}

\section{Compliance with ethical standards}

\section{Conflicts of interest}

Dr. Schellongowski reports a grant from the European Society of Intensive Care Medicine (ESICM), personal fees from Maquet (ongoing) and Novalung (past), outside the submitted work, and has co-coordinated the 2018 edition of the ESICM NEXT acute respiratory distress syndrome fellowship, which was sponsored by Medtronic. Dr. Combes reports grants from Maquet, personal fees from Maquet and Baxter, outside the submitted work. Dr. Hylander Møller report no COls.

Received: 6 October 2018 Accepted: 12 November 2018

Published online: 21 November 2018

\section{References}

1. Morelli A, Del Sorbo L, Pesenti A, Ranieri VM, Fan E (2017) Extracorporeal carbon dioxide removal (ECCO2R) in patients with acute respiratory failure. Intensive Care Med 43:519-530

2. Combes A, Brodie D, Chen YS, Fan E, Henriques JPS, Hodgson C, Lepper PM, Leprince P, Maekawa K, Muller T, Nuding S, Ouweneel DM, Roch A, Schmidt
M, Takayama H, Vuylsteke A, Werdan K, Papazian L (2017) The ICM research agenda on extracorporeal life support. Intensive Care Med 43:1306-1318

3. Gattinoni L, Quintel M (2017) Do we need randomized clinical trials in extracorporeal respiratory support? No. Intensive Care Med 43:1866-1868

4. Vincent $J$, Brochard $\sqcup$ (2017) Do we need randomized clinical trials in extracorporeal respiratory support? We are not sure. Intensive Care Med 43:1869-1871

5. Combes A, Pesenti A, Brodie D (2017) Do we need randomized clinical trials in extracorporeal respiratory support? Yes. Intensive Care Med 43:1862-1865

6. Bein T, Brodie D (2017) Understanding ethical decisions for patients on extracorporeal life support. Intensive Care Med 43:1510-1511

7. Combes A, Hajage D, Capellier G, Demoule A, Lavoue S, Guervilly C, Da Silva D, Zafrani L, Tirot P, Veber B, Maury E, Levy B, Cohen Y, Richard C, Kalfon P, Bouadma L, Mehdaoui H, Beduneau G, Lebreton G, Brochard L, Ferguson ND, Fan E, Slutsky AS, Brodie D, Mercat A, Eolia Trial Group R, Ecmonet (2018) Extracorporeal membrane oxygenation for severe acute respiratory distress syndrome. N Engl J Med 378:1965-1975

8. Fan E, Gattinoni L, Combes A, Schmidt M, Peek G, Brodie D, Muller T, Morelli A, Ranieri VM, Pesenti A, Brochard L, Hodgson C, Van Kiersbilck C, Roch A, Quintel M, Papazian L (2016) Venovenous extracorporeal membrane oxygenation for acute respiratory failure: a clinical review from an international group of experts. Intensive Care Med 42:712-724

9. Ponikowski P, Voors AA, Anker SD, Bueno H, Cleland JGF, Coats AJS, FalkV, Gonzalez-Juanatey JR, Harjola VP, Jankowska EA, Jessup M, Linde C, Nihoyannopoulos P, Parissis JT, Pieske B, Riley JP, Rosano GMC, Ruilope LM, Ruschitzka F, Rutten FH, van der Meer P, Group ESCSD (2016) 2016 ESC Guidelines for the diagnosis and treatment of acute and chronic heart failure: The Task Force for the diagnosis and treatment of acute and chronic heart failure of the European Society of Cardiology (ESC)Developed with the special contribution of the Heart Failure Association (HFA) of the ESC. Eur Heart J 37:2129-2200

10. Chen YS, Lin JW, Yu HY, Ko WJ, Jerng JS, Chang WT, Chen WJ, Huang SC, Chi $\mathrm{NH}$, Wang CH, Chen LC, Tsai PR, Wang SS, Hwang JJ, Lin FY (2008) Cardiopulmonary resuscitation with assisted extracorporeal life-support versus conventional cardiopulmonary resuscitation in adults with in-hospital cardiac arrest: an observational study and propensity analysis. Lancet 372:554-561

11. Barbaro RP, Odetola FO, Kidwell KM, Paden ML, Bartlett RH, Davis MM, Annich GM (2015) Association of hospital-level volume of extracorporeal membrane oxygenation cases and mortality. Analysis of the extracorporeal life support organization registry. Am J Respir Crit Care Med 191:894-901

12. Abrams D, Garan AR, Abdelbary A, Bacchetta M, Bartlett RH, Beck J, Belohlavek J, Chen YS, Fan E, Ferguson ND, Fowles JA, Fraser J, Gong M, Hassan IF, Hodgson C, Hou X, Hryniewicz K, Ichiba S, JakobleffWA, Lorusso R, MacLaren G, McGuinness S, Mueller T, Park PK, Peek G, Pellegrino V, Price S, Rosenzweig EB, Sakamoto T, Salazar L, Schmidt M, Slutsky AS, Spaulding C, Takayama H, Takeda K, Vuylsteke A, Combes A, Brodie D, International EN, The Extracorporeal Life Support O (2018) Position paper for the organization of ECMO programs for cardiac failure in adults. Intensive Care Med 44:717-729

13. Combes A, Brodie D, Bartlett R, Brochard L, Brower R, Conrad S, De Backer D, Fan E, Ferguson N, Fortenberry J, Fraser J, Gattinoni L, Lynch W, MacLaren G, Mercat A, Mueller T, Ogino M, Peek G, Pellegrino V, Pesenti A, Ranieri M, Slutsky A, Vuylsteke A, International EN (2014) Position paper for the organization of extracorporeal membrane oxygenation programs for acute respiratory failure in adult patients. Am J Respir Crit Care Med 190:488-496

14. Harrington D, Drazen JM (2018) Learning from a trial stopped by a data and safety monitoring board. N Engl J Med 378:2031-2032

15. Hardin CC, Hibbert K (2018) ECMO for severe ARDS. N Engl J Med 378:2032-2034

16. Karagiannidis C, Brodie D, Strassmann S, Stoelben E, Philipp A, Bein T, Muller T, Windisch W (2016) Extracorporeal membrane oxygenation: evolving epidemiology and mortality. Intensive Care Med 42:889-896 